\title{
Mothers' Knowledge and Attitudes about HPV Vaccination to Prevent Cervical Cancers
}

\author{
Dilek Kose ${ }^{1}$, Unal Erkorkmaz ${ }^{2}$, Nursan Cinar ${ }^{1 *}$, Sevin Altınkaynak $^{1}$
}

\begin{abstract}
Background: Cervical cancer which is one of the most preventable cancers is an important public health problem worldwide, and especially in developing countries. The aim of this study was to determine knowledge and attitudes about the HPV vaccination of mothers with 0 - to 18-year old children. Materials and Methods: Written approval was taken from the local authorities. The study subjects consisted of 799 mothers who agreed to participate. The data were collected via a "Personal Information Form" which included 30 questions that were prepared by the researchers themselves in line with the literature. The data were collected by face to face interviews with the mothers. Analyses were performed using commercial software. Results: The mean age of the mothers who participated in the study was $32.0 \pm 6.52$, and $88.1 \%$ reported no information about HPV, and $83.5 \%$ no information about HPV vaccination. Only $0.7 \%$ of the mothers had daughters who had HPV vaccination, and 44.3\% of the mothers who had sons were found out to be indecisive about having HPV vaccination. There was a significant corelation between the educational status of the mothers and their knowledge about HPV vaccination $(\mathbf{p}<0.05)$. However, there was no significant correlation in terms of economic conditions $(p>0.05)$. Conclusions: This study suggested that mothers had very little information on HPV and HPV vaccination. Knowledge of the disease and its vaccination is an essential factor for the success of the vaccination program. It is of great importance that mothers are trained in this subject by health professionals.
\end{abstract}

Keywords: Cervical cancer - human papilloma virus - vaccine - mothers' knowledge and attitudes - Turkey

Asian Pac J Cancer Prev, 15 (17), 7263-7266

\section{Introduction}

Cervical cancer which is one of the most preventable cancers is an important public health problem worldwide, and especially in developing countries (Dochez et al., 2014; Duman; Y1lmazel, 2014). Cervical cancer is the fourth most common cancer in women, with an estimated 528,000 new cases in 2012.There were an estimated 266.000 deaths from cervical cancer worldwide in 2012, accounting for $7.5 \%$ of all female cancer deaths (Globan, 2012). According to the data from Health Statistics Annual of Ministry of Health in Turkiye, it is reported that the prevalence of cervical cancer is 7.1 in 100000. (Ministry of Health - Health Statistics Annual, 2012). Almost the whole cervical cancer cases are related with human papilloma virus (HPV).

Human papillomavirus (HPV) infection of the genital mucosa is a common, sexually transmitted condition and there is now conclusive evidence for its role in the aetiology of cervical cancer (Marlow et al. 2007; Dochez et al., 2014). Human papilloma virus family has 120 types 40 of which cause anogenital infections. (Ozan et al., 2011). Although most infections are asymptomatic and clear on their own, persistent genital HPV infection is associated with several sequelae, including cervical cancer in women
(National Cancer Institute 2014). HPV types 16 and 18 are responsible for approximately $70 \%$ of cervical cancers worldwide (Devereaux Walsh et al., 2008; Robitz et al., 2011; Sanders Thomson et al., 2011).

Two forms of vaccines have recently been approved for use for the primary prevention of cervical cancer (Devereaux Walsh et al. 2008; Drug and Food Administration, 2014). The quadrivalent vaccine also prevents vaginal, vulvar, and anal dysplasia as well as genital warts, and is also indicated for males. Advisory Committee on Immunization Practices (ACIP) currently recommends vaccination of females and males aged 11 to 13, with catch up vaccination for females aged 13 to 26 . (Advisory Committee on Immunization Practices 2010). In Turkey, the HPV vaccine has been used since April 2007 (Yilmazel and Duman, 2014).

There are many factors effecting the family's approval of vaccination for their kids and its application. Introduction of the HPV vaccine has proceeded slowly in many countries because of low knowledge about cervical cancer, high vaccine cost, and cultural preferences surrounding vaccinating young girls (Tsui et al., 2009; Madhivanan et al., 2014). Studies have shown that ageat-vaccination is an important factor in parental decisionmaking about immunizing daughter against HPV infection 
(Marlow et al., 2007; Madhivanan et al., 2014).

The aim of this study was to determine mothers' who have 0 - to 18-year old children, knowledge and attitudes about the HPV vaccination.

\section{Materials and Methods}

This descriptive and correlational study was approved by the Ethical Board in Sakarya University and study started after receiving approval from related local authorities. Study was conducted between May- June 2014. Universe of the study consisted of all the mothers who applied to pediatric outpatient clinic at two state hospitals in Sakarya province and who have children between 0-18 years-old. Sample of the study consisted of 799 mothers who agreed to participate. The participation criteria; mothers who were over 18 years old and have healthy children between 0-18 years old, who have no communication problems and who were voluntary to participate in the study. The mothers of the children in Paediatric ICU and the ones who have disabled children were not included in the study.

The data were collected via a "Personal Information Form" which included 30 questions that were prepared by the researchers themselves in line with the literature (Madhivanan et al., 2014; Duman and Yilmazel, 2014). Personal Information Form includes items on age, educational status, economical status, occupation, mother's working status and questions regarding knowledge and attitudes about the HPV (if they knew about the vaccination, when and to whom the vaccination was performed, etc.).

The participating mothers were informed of the purpose of the study and the methods to be used and signed an informed consent statement. The data were collected by face to face interviews with the mothers.

Chi-square test was used to compare between the mothers' knowledge and attitude towards HPV and their sociodemographic characteristics. A p $<0.05$ was considered statistically significant. Analyses were performed using commercial software (IBM SPSS Statistics 20, SPSS Inc. An IBM Corp., Armonk, NY)

\section{Results}

The average age of the mothers participated in the study was detected to be $32.0 \pm 6.52(\min =18, \max =55)$. A total of $63 \%$ of the mothers were primary school, $25.7 \%$ were high school and $11.4 \%$ were university graduates. $84.5 \%$ of the mothers stated that they did not work and $69.6 \%$ stated that they had a medium level income. A total of $42.9 \%$ of the mothers had 2 children who were alive. Of the mothers who had children between the ages of $0-18$, a total of $27.2 \%$ had daughters, $26.7 \%$ had sons and $46.2 \%$ had both daughters and sons (Table 1).

It was found out that a total of $88.1 \%$ of the mothers $(n=704)$ had no information about HPV, 73.7\% $(n=589)$ did not know how the infection was transmitted and $83.5 \%$ did not have any information on HPV vaccination. A total of $27.1 \%(n=35)$ of 132 women who declared that they knew about the vaccination, stated that they learned from a health staff, $61.2 \%(n=79)$ stated that they learned from communication tools like television, radio, newspaper and internet, and $11.6 \%(n=15)$ learned from people like friends or relatives. It is found out that $83.2 \%$ of the mothers did not know at what age vaccination was applied and $84.1 \%$ did not know to whom it was applied. A total of $0.7 \%$ of the mothers who had daughters were found out to be vaccinated against HPV, $44.3 \%$ of the mothers who had sons were found out to be hesitant about being vaccinated or not.

It was found out that there was an advanced level of statistically significant difference with respect to mothers' knowledge about HPV ( $\mathrm{p}<0.001)$, transmission of HPV $(p<0.001)$, HPV vaccination $(p<0.001)$, the sex to which vaccination is applied $(\mathrm{p}<0.001)$, and about the age vaccination is applied at $(\mathrm{p}<0.001)$ according to the mothers' education levels (Table 2).

According to the economic situation of mothers, there was a statistically significant difference between knowledge about HPV $(\mathrm{p}<0.001)$, HPV vaccination $(\mathrm{p}<0.001)$, and the sex to which vaccination is applied

Table 1. Socio-Demographic Characteristics of the Study Participants

\begin{tabular}{llc}
\hline Variables & & Categories \\
\hline Age, years & & $32.01 \pm 6.52$ \\
Educational Status & Primary school grad. & $503(63)$ \\
& High school grad. & $205(25.7)$ \\
& University grad. & $91(11.4)$ \\
Study group & Yes & $124(15.5)$ \\
& No & $675(84.5)$ \\
Economical status & Bad & $20(2.5)$ \\
& Middle level & $556(69.6)$ \\
Number of children & Good & $223(27.9)$ \\
who are alive & 2 & $226(28.3)$ \\
& 3 or more & $343(42.9)$ \\
Sex of the baby & Girl & $230(28.8)$ \\
& Boy & $217(27.2)$ \\
*Data were shown as $\mathrm{n}(\%)$ and mean \pm standard deviation & $213(26.7)$ \\
\end{tabular}

Table 2. Comparison of Mothers' Knowledge about HPV and HPV Vaccination with Respect to their Education Levels

\begin{tabular}{|c|c|c|c|c|c|}
\hline & $\begin{array}{l}\text { Edu } \\
\text { Primary school } \\
\text { graduate } \\
(\mathrm{n}=503)\end{array}$ & $\begin{array}{l}\text { Icational sta } \\
\text { High school } \\
\text { graduate } \\
(n=205)\end{array}$ & $\begin{array}{l}\text { tus } \\
\text { University } \\
\text { Graduate } \\
(\mathrm{n}=91)\end{array}$ & $\chi^{2}$ & $\mathrm{p}$ \\
\hline \multicolumn{6}{|l|}{ Knows about HPV } \\
\hline Yes & $28(5.6)$ & $38(18.5)$ & $29(31.9)$ & 62.513 & $<0.001$ \\
\hline No & $475(94.4)$ & $167(81.5)$ & $62(68.1)$ & & \\
\hline \multicolumn{6}{|c|}{ Knows about HPV transmission } \\
\hline Yes & $101(20.1)$ & $67(32.7)$ & $42(46.2)$ & 32.87 & $<0.001$ \\
\hline No & $402(79.9)$ & $138(67.3)$ & $49(53.8)$ & & \\
\hline \multicolumn{6}{|c|}{ Knows about HPV vaccination } \\
\hline Yes & $55(10.9)$ & $44(21.5)$ & $33(36.3)$ & 40.733 & $<0.001$ \\
\hline No & $448(89.1)$ & $161(78.5)$ & $58(63.7)$ & & \\
\hline \multicolumn{6}{|c|}{ Knows which sex vaccination is applied to } \\
\hline Girls & $32(6.4)$ & $27(13.2)$ & 19 (20.9) & 41.399 & $<0.001$ \\
\hline Both girls and boys & ys $18(3.6)$ & $20(9.8)$ & $11(12.1)$ & & \\
\hline Doesn’t know & $453(90.1)$ & $158(77.1)$ & $61(67.0)$ & & \\
\hline \multicolumn{6}{|c|}{ Knows at what age vaccination is applied to } \\
\hline Yes & $66(13.1)$ & $39(19.0)$ & $29(31.9)$ & 20.405 & $<0.001$ \\
\hline No & $437(86.9)$ & $166(81.0)$ & $62(68.1)$ & & \\
\hline
\end{tabular}


Table 3. A Comparison of Mothers' Knowledge about HPV and HPV Vaccination with Respect to their Economic Situation

\begin{tabular}{|c|c|c|c|c|}
\hline & \multicolumn{2}{|c|}{ Economic condition } & \multirow[t]{2}{*}{$\chi^{2}$} & \multirow[t]{2}{*}{$\mathrm{p}$} \\
\hline & $\begin{array}{l}\text { Bad-medium level } \\
\qquad(\mathrm{n}=576)\end{array}$ & $\begin{array}{c}\text { Goods } \\
(n=223)\end{array}$ & & \\
\hline \multicolumn{5}{|l|}{ Knows about HPV } \\
\hline Yes & $48(8.3)$ & $47(21.1)$ & 24.918 & $<0.001$ \\
\hline No & $528(91.7)$ & $176(78.9)$ & & \\
\hline \multicolumn{5}{|c|}{ Knows about HPV transmission } \\
\hline Yes & $142(24.7)$ & $68(30.5)$ & 2.830 & 0.092 \\
\hline No & $434(75.3)$ & $155(69.5)$ & & \\
\hline \multicolumn{5}{|c|}{ Knows about HPV vaccination } \\
\hline Yes & $71(12.3)$ & $61(27.4)$ & 26.325 & $<0.001$ \\
\hline No & $505(87.7)$ & $162(72.6)$ & & \\
\hline \multicolumn{5}{|c|}{ Knows which sex vaccination is applied to } \\
\hline Girls & $48(8.3)$ & $30(13.5)$ & 11.547 & 0.003 \\
\hline Both girls and boys & $28(4.9)$ & $21(9.4)$ & & \\
\hline Doesn't know & $500(86.8)$ & $172(77.1)$ & & \\
\hline \multicolumn{5}{|c|}{ Knows at what age vaccination is applied to } \\
\hline Yes & $90(15.6)$ & $44(19.7)$ & 1.942 & 0.163 \\
\hline No & $486(84.4)$ & $179(80.3)$ & & \\
\hline
\end{tabular}

$(p=0.003)$. However, there was no significant difference between the knowledge about HPV transmission and about the age HPV vaccination is applied at $(\mathrm{p}=0.092$ and $\mathrm{p}=0.163$ respectively) (Table 3 ).

\section{Discussion}

This is a study which aims to detect the knowledge and attitudes of mothers towards HPV vaccination that intends to avoid cervical cancers in Sakarya district of Marmara Region in Turkey.

It was found out that a majority of, $88.1 \%$ of mothers did not have any knowledge about HPV. In a study conducted by Marlow et al. (2007), it was seen that $72.8 \%$ of the mothers who have daughters between the ages of 8-14 had never heard of HPV before. In Sanders Thompson et al. (2011)'s study, only 124 (62\%) participants had heard of HPV. Most mothers (27.7\%) hadn't heard of HPV previously (Berenson et al. 2014). A study by Tozzi et al.(2009) in Italy revealed that $33.5 \%$ of the mothers who have daughters between the ages of 10-12 had never heard of HPV previously. In the studies in Turkiye, it is seen that $55 \%$ of the mothers had never heard of HPV before (Dursun et al. 2009) and 66.4\% of the mothers had no knowledge about HPV (Ozan et al. 2011). In Ghojazadeh et al (2012)'s study, 76\% of parents said that they hado no information about HPV.

In this study, $83.5 \%$ of the mothers stated that they had no knowledge about HPV vaccination. In the studies conducted it is seen that $53.7 \%$ of the mothers (Bulbul et al., 2013), 55.4\% of the mothers (Ozan et al., 2011), $50.7 \%$ of the mothers (Berenson et al.2014) and $42.3 \%$ of the mothers (Pinar et al., 2010) had no knowledge about HPV vaccination. In California, Robitz et al. (2011) stated that $45.7 \%$ of the families had never heard of vaccination previously. In Kruiroongroj et al (2014)'s study, majority of the respondents $(70 \%)$ were aware of the HPV vaccine.

Of the 132 people who expressed that they knew about vaccination, $27.1 \%(n=35)$ stated that they learned about it from a health Professional, 61.2\% ( $n=79)$ of them learned it from communication tools like television, radio, newspapers or internet, $11.6 \%(n=15)$ learned it from friends or relatives. In a study by Tozzi et al. (2009), 50.2\% of the ones who know about HPV stated that they learned it from a doctor, $45,8 \%$ stated that they learned from television, radio or internet, $4.1 \%$ stated that they learned from friends or relatives. In their study, Madhivanan et al. (2014) stated that $85 \%$ of the families learned from television, $79 \%$ learned from newspapers and radio, $43 \%$ learned from the internet and $86 \%$ learned from the doctors. In Robitz et. al.(2011)'s study, 69.2\% of the families replied "no" to the question "did any doctor or health agency during last year suggest that your daughter should be vaccinated against HPV?". In Ghojazadeh et al (2012)'s study, parents' $42 \%$ claimed that they had obtained such information by studying medical resiources and 36\% from Internet and friends. In Kruiroongroj et al (2014)'s study, Tv/radio, newspapers/magazines (88\%) were major information, followed by hospital/health care providers $(66 \%)$.

Prophylactic vaccines against human papillomavirus (HPV) are expected to be available for public use by 2007 and likely will be targeted to preadolescent children. Parental acceptance of these vaccines will be critical for their success (Dempsey et al., 2006). 0.7\% of the mothers with daughters were detected to have HPV vaccination while $44.3 \%$ of the mothers with sons were found out to be hesitant about HPV vaccination. In the study by Sanders Thompson et al. (2011), it is seen that only $16.5 \%$ of the girls were vaccinated against HPV. A study in Los Angeles County, $24.6 \%$ of parents reported that their daughters had received at least 1 dose of HPV vaccine (Robitz et al. 2011). In a study by Ozan et al. (2011), $42 \%$ of the mothers had no idea about recommending the vaccination to their daughters, and $58.9 \%$ had no idea about recommending it to their sons. Devereaus Walsh et al. (2008) stated that the majority of study participants believed that boys should be vaccinated as well as girls $(91.2 \%)$. In the study by Kilic et al. (2012) $45.5 \%$ of the mothers was willing to have their daughters vaccinated aganist HPV but most of mothers $(84.1 \%)$ did not want this vaccination as they did not have sufficient knowledge about vaccine.

Mothers have been shown to be highly involved in their children's healthcare decisions, especially with regards to HPV vaccination (Berenson et al. 2014). In this study there is a significant correlation between the mothers' education level and their knowledge about HPV. It is seen that the higher education level a mother has, the more knowledge she has about HPV (Table 1). In the studies, it is clear that there is a significant correlation between mothers' education levels and their knowledge on HPV and this shows a paralellism with our study (Ozan et al., 2011; Ghojazadeh et al 2012 ).

In our study, there is a significant correlation between the mothers' education level and their knowledge about HPV vaccination. In the study by Bulbul et al. (2013), it is seen that there is a correlation between the mothers' educational status and their methods to avoid from cervical cancers, $81.9 \%$ of the mothers are stated to use vaccination as a protective method. About the mothers' education levels and their knowledge about HPV vaccination, the 


\section{Dilek Kose et al}

studies by Sanders Thompson et al. (2011) and Pınar et al. (2010) also suggest that there is a significant correlation. However, the study by Ozan et al. (2011) states that there is no significant difference.

According to mothers' economic conditions, there is no significant correlation between their knowledge about HPV. However, there is a significant relationship between a high income and the mothers' awareness of HPV (Sanders Thompson et al. 2011).

The limitation of this study is the fact that the results of this study include the data of Sakarya district only, so it cannot be generalized for Turkey. Similar studies for varied populations in Turkey should be performed.

As a result of this study, it is shown that mothers in a wide range do not have any information about HPV and HPV vaccination. The ones who have some information about the subjects state that they learned about the subject from televisions, radios, newspapers or the internet. Getting knowledge from the health professionals is of a small extent. Based on this result, it can be suggested that doctors and nurses are informed about this situation and mothers are trained by health professionals on this subject. The attempts to protect from this disease will be more successful if particularly mothers' awareness on this subject is raised.

\section{References}

Advisory Committee on Immunization Practices (2010). FDA licensure of bivalent human papilloma virus vaccine (HPV2, Cervarix) for use in females and updated HPV vaccination recommendations from the Advisory Committee on Immunization Practices (ACIP). MMWR Morb MortalWklyRep, 59, 626-29.

Berenson AB, Laz TH, Hirt JM, et al (2014). Effect of the decision-making process in the family on HPV vaccination rates among adolescents 9-17 years of age. Hum Vaccin Immunothe, $\mathbf{1 0}$.

Bulbul S, Yalcin S, Araz NC, et al. (2014). Thoughts of mothers with children 0-15 years of age about cervical cancer and HPV vaccination in Anatolia. Turkish J Pediatric Dis, 2, 73-8 (in Turkish).

Dempsey A F, Zimet GD, Davis RL et al (2006). Information about HPV papillomavirus vaccines: a randomized intervention study of written. Pediatrics, 117, 1486-93.

Devereaux Walsh C, Gera A, Shah M, et al (2008). Public knowledge and attitudes towards Human Papilloma Virus (HPV) vaccination. BMC Public Health, 8, 368.

Dochez C, Bogers JJ, Verhelsta R, et al (2014). HPV vaccines to prevent cervical cancer and genital warts: an update. Vaccine, 32, 1595-601.

Dursun P, Kuficu E, Zeyneloglu HB, et al (2009). 1The knowledge and attitudes of the mothers who have adolescent children between the ages of 10-15. Turkish J Obstetrics Gynaecology, 6, 206-10 (in Turksih).

Food and Drug Administration (2014). FDA Approves New Vaccine for Prevention of Cervical Cancer. http://www. fda.gov/newsevents/newsroom/pressannouncements/ ucm187048.htm, Access date: May 16,2014.

Globan 2012, Estimated cancer insidence, mortality and prevalence worldwide in $2012 \mathrm{http} / /$ globocan .iarc.fr/Pages/ fact_sheets_cancer.aspx, Access date: April 06, 2014

Ghojazadeh M, Naghavi-Behzad M, Azar ZF, et al (2012). Parental knowledge and attitudes about papilloma virus in
Iran. Asian Pac J Cancer Prev, 13, 6169-73.

Kilic A, Seven M, Guvenc G, Akyuz A, Ciftci S (2012). Acceptance of human papillomavirus vaccine by adolescent girls and their parents in Turkey. Asian Pac J Cancer Prev, 13, 4267-72.

Kruiroongroj S, Chaikledkaew U, Thavorncharoensap M (2014). Knowledge, acceptance, and willingness to pay for human papilloma virus (HPV) vaccination among female parents in Thailand. Asian Pac J Cancer Prev, 15, 5469-74.

Madhivanan P, Srinivas V, Marlow L, et al. (2014) Indian parents prefer vaccinating their daughters against HPV at older ages. Asian Pac J Cancer Prev, 15 (1), 107-10

Marlow LAV, Waller J, Wardle J (2007). Parental attitudes to pre-pubertal HPV vaccination. Vaccine, 25, 1945-52.

National Cancer Institute Fact sheet (2006). Human papillomaviruses and cancer: Questions and answers. http:// www.cancer.gov/cancertopics/factsheet/Risk/HPV, Access date: May 16, 2014.

Ozan H, Demir BC, Atik Y, Gumus E, Ozerkan K (2011). Detecting the knowledge levels of patients who admitted to obstetrics and gynaecology department, about human papilloma virus and HPV vaccination. Uludag University $J$ Fac Medicine, 37, 145-48 (in Turksih).

Pınar G, Topuz S, An S et al (2010). The HPV vaccine and cervical cancer-related knowledge levels of the women who applied to Baskent University Hospital of Obstetrics and Gynecology Department. Turkish J Gynecologic Oncol, 1, 11-18 (in Turksih).

Robitz R, Gottlieb SL, De Rosa CJ, et al (2011). Parent attitudes about school requirements for human papillomavirus vaccine in high-risk communities of Los Angeles, California. Cancer Epidemiol Biomarkers Prev, 20, 1421-29.

Sanders Thompson VLS, Arnold LD, Notaro SR (2011). African American parents' attitudes toward HPV vaccination. Ethn Dis, 21, 335-41.

Tozzi AE, Ravà L, Stat D, et al (2009). Attitudes towards HPV immunization of Italian mothers of adolescent girls and potential role of health professionals in the immunization program. Vaccine, 27, 2625-29

Tsui J, LaMontagne DS, Levin C, et al (2009). Policy development for human papillomavirus vaccine introduction in low-resource settings. Open Vaccine J, 2, 113-22.

The Republic of Turkiye, Ministry of Health (2012). Health Statistics Annual, Access date: June 04, 2014.

Yılmazel G, Duman NB (2014). Knowledge, attitudes and beliefs about cervical cancer and human papilloma virus vaccination with related factors in Turkish university students. Asian Pac J Cancer Prev, 15, 3699-704. 